two years out of hours workload in east London general practice. $B M$ 1989;299:368-70.

23 Bosanquet N, Leese B. Family doctors and economic incentives. Aldershot: Dartmouth, 1989.

(Accepted 4 December 1991 )

\section{Appendix \\ Derivation of deprivation scores and deprivation indices for general practitioner workload}

Assuming that there are $\mathrm{k}$ electoral wards in England under consideration, then there are, for example, $\mathrm{N}_{\mathrm{i}}(\mathrm{i}=1, \ldots, \mathrm{k})$ men in ward $i$ aged 16 to 64 of which $M_{i}$ are of the manual socioeconomic group and the remainder are in the nonmanual group. The odds ratio for excess of consultation is 1.06 (table I) for the manual group and this leads to an effective number of men in the ward for consultation as

$\mathrm{n}_{\mathrm{i}}=\left(\mathrm{N}_{\mathrm{i}}-\mathrm{M}_{\mathrm{i}}\right)+1 \cdot 06 \mathrm{M}$

$=\mathrm{N}_{\mathrm{i}}+0 \cdot 06 \mathrm{M}$.

The total number of these men in England is the sum of their numbers in each ward, that is $N=\Sigma N_{i}$, the total effective number of men is $n=\Sigma n_{i}$ and their ratio is $W=N / n$. The individual $\mathrm{n}_{\mathrm{i}}$ of each electoral ward is then scaled relative to England as a whole and expressed as a proportion of its own population of men, giving

$\mathrm{p}_{\mathrm{Si}}=\mathrm{Wn}_{\mathrm{i}} / \mathrm{N}_{\mathrm{i}}$

The $\mathrm{S}$ denotes adjustment for socioeconomic group.

Similar calculations for tenure ( $\mathrm{T})$, car ownership (C), and country of birth (B) give for each ward $\mathrm{p}_{\mathrm{Ti}}, \mathrm{p}_{\mathrm{Ci}}$ and $\mathrm{p}_{\mathrm{Bi}}$ and their product is the deprivation score

$\mathrm{DS}_{\mathrm{i}}=\mathrm{p}_{\mathrm{Si}} \mathrm{p}_{\mathrm{Ti}} \mathrm{p}_{\mathrm{Ci}} \mathrm{p}_{\mathrm{Bi}}$

which provides the final scaling factor relating to men in the ward, taking account of the various socioeconomic characteristics (the deprivation score of table II).

Similar calculations are applied to children, women, and elderly people.

For each electoral ward the actual age-sex structure is available so that by applying the age-sex specific consultation rates from the national morbidity study to the individual wards the expected number of consultations are calculated (table III, column 2) and totalled for England. The weighted consultations take account of the ward specific deprivation scores for the four groups standardised against the total number of expected consultations for England. Finally, the deprivation index (table III, column 4) is the ratio of these two consultation estimates.

\title{
Screening for cervical cancer by direct inspection
}

\author{
Veena Singh, Ashok Sehgal, Usha K Luthra
}

\section{Abstract}

Objective-To assess the efficacy of visual screening for cervical cancer in the maternal and child health setting.

Design-Clinical and cytological screening.

Setting - Maternal and child health centres, Delhi.

Subjects -44970 women attending the centres from May 1988 to March 1991.

Results -238 cancers in early stages (0-IIa) were detected cytologically and proved through biopsy. Prevalence of cancer in women defined as high risk through examination by speculum was $29 / 1000$ as compared to $1 \cdot 53 / 1000$ among women with a normal looking cervix. Though only $11.4 \%$ women belonged to the high risk category, $63 \%$ had early stage cancer. If all women with bleeding symptoms were included in the high risk category, the yield of cancer would be $71.4 \%(170 / 238)$ by referring only $15.6 \%$ of women attending maternal and child health centres for further evaluation through cytology or colposcopy.

Conclusion-Though visual screening is a suboptimal strategy in comparison to the cytological screening, it may be useful where there is a heavy load of prevalent cancer and where cytological screening may not be available for years to come.

\section{Introduction}

Cervical cancer is the leading malignancy among Indian women, with about 90000 new cases occurring every year. Unfortunately the facilities for nationwide cytological screening do not exist because trained staff are few. It has been estimated that even with a 12 -fold increase in staff trained in cytology, only about a quarter of women over the age of 35 could be screened by the turn of the century. Therefore, there is a distinct need for an alternative strategy to detect cancer at an early stage. One such strategy is visual screening: the visual examination of the cervix of asymptomatic women so as to detect cancer at an early stage. ' 'Such a strategy is not expected to decrease the incidence of invasive cancer, but it would decrease mortality through early detection.

We have shown that it is possible to detect about $50 \%$ of cervical cancers at an early stage (stage 0 -IIa) through visual screening. ${ }^{2}$ This is in sharp contrast to the prevailing situation, when only $5 \%$ of women with cancer report to the treatment centre at an early stage. Such a strategy, if feasible, is to be implemented in the existing maternal and child health services. This paper assesses the efficacy of direct visual inspection of the cervix for early detection of cervical cancer.

\section{Materials and methods}

A total of 44970 women attending maternal and child health centres in Delhi were screened clinically as well as cytologically. These centres provide maternal and child health care to the women of reproductive age, including gynaecological check ups, antenatal services, family planning services, and treatment for infertility. Most women attending the centres had minor symptoms such as vaginal discharge, backache, and vague abdominal pain.

Cancers were detected through cytology and confirmed through biopsy directed by colposcopy. The clinical symptoms and the findings of the vaginal pelvic examination as well as of examination by speculum were recorded on a pretested form. The rates of malignancy per 1000 women screened were calculated for women presenting with each symptom. Women with symptoms with similar malignancy rates were grouped into four categories: symptom free; symptoms other than bleeding, including vaginal discharge, painful abdomen, backache, itching vulva; menstrual problems such as scanty periods, menstrual irregularities, prolonged periods, heavy periods; bleeding symptoms, which consisted of intermenstrual bleeding and contact bleeding (table I).

The rates of malignancies per 1000 women screened were calculated for women with different clinical signs as described on examination by speculum. The clinical signs with similar malignancy rates were grouped into three categories: normal looking cervix; a low risk category that included cervicitis, cervical erosions, cervical polyps, and prolapsed uterus; a high risk category that included erosions that bled on touch, small growths, and a suspicious looking cervix. We calculated $95 \%$ confidence intervals for the prevalence of cancer in different categories of symptoms and signs. ${ }^{3}$
Correspondence to: Dr Singh.

BMF 1992;304:534-5 


\section{Results}

A total of 44970 women were screened and 238 women $(5 \cdot 3 / 1000)$ were found to have cancer proved by biopsy. None of the 272 asymptomatic women and 144 of the 36620 women with symptoms other than bleeding had cancer $(3 \cdot 9 / 1000)$. Nineteen of the 5448 women with menstrual problems $(3 \cdot 48 / 1000)$ and 75 of the 2360 women with bleeding symptoms $(28 \cdot 5 / 1000)$ had cervical cancer (table I).

Twenty one of the 13640 women with a normal looking cervix had cervical cancer $(1 \cdot 53 / 1000)$ compared with 68 of the 26195 women $(2 \cdot 6 / 1000)$ in the low risk category and 149 of the $5135(29 / 1000)$ women in the high risk category (table II). These cancers were staged by clinical assessment according to the 1987 International Federation of Gynaecology and Obstetrics (FIGO) classification, and were found to vary from carcinoma in situ to stage IIa.

Only $0.6 \%(272)$ of the women had no symptoms. A total of $36620(81.4 \%)$ presented with symptoms other than bleeding, $5448(12 \%)$ had menstrual problems, and $2630(5 \cdot 8 \%)$ presented with bleeding symptoms. Examination by speculum showed that $13640(30 \cdot 3 \%)$ women had a normal looking cervix, $26195(58 \cdot 2 \%)$ had symptoms in the low risk category, and 5135 $(11 \cdot 4 \%)$ had symptoms in the high risk category.

Screening through direct inspection of the cervix picked up 149 of the 238 cancers proved by biopsy: a sensitivity of $62.6 \%$. The specificity of screening by direct inspection was $88.9 \%$ as of the 44732 women with biopsy samples that were not cancerous, 39746 were found to be non-cancerous by direct inspection. The positive predictive value was $2.9 \%$ as 149 suspected cancers found by direct inspection (in

TABLE I-Prevalence of cervical cancer in women with different symptoms

\begin{tabular}{|c|c|c|c|}
\hline & $\begin{array}{c}\text { No (\%) of } \\
\text { women screened }\end{array}$ & $\begin{array}{c}\text { No }(\%) \text { of } \\
\text { cancers detected }\end{array}$ & $\begin{array}{l}\text { Rate of malignancy per } \\
1000 \text { women screened } \\
(95 \% \text { confidence interval })\end{array}$ \\
\hline No symptoms & $272(0 \cdot 6)$ & & \\
\hline Symptoms other than bleeding & $36620(81 \cdot 4)$ & $144(61)$ & $3.9(3.3$ to 4.5$)$ \\
\hline Menstrual problems & $5448(12 \cdot 0)$ & $19(8)$ & $3.5(1.9$ to $5 \cdot 1)$ \\
\hline Bleeding & $2630(5 \cdot 8)$ & $75(32)$ & $28.5(22.2$ to 34.9$)$ \\
\hline Total & 44970 & 238 & $5.3(4.6$ to $5 \cdot 9)$ \\
\hline
\end{tabular}

TABLE II-Prevalence of cervical cancer according to clinical signs

\begin{tabular}{lcccc}
\hline & No $\%$ of & & $\begin{array}{c}\text { Rate of } \\
\text { women } \\
\text { malignancy per } \\
1000 \text { women } \\
\text { screened } \\
(95 \% \text { confidence } \\
\text { interval })\end{array}$ \\
\hline $\begin{array}{l}\text { Normal looking cervix } \\
\text { Low risk category (including cervicitis, cervical erosions, } \\
\text { cervical polyps, prolapsed uterus) }\end{array}$ & $13640(30 \cdot 3)$ & $\begin{array}{c}\text { No }(\%) \text { of } \\
\text { cancers } \\
\text { detected }\end{array}$ & $21(9)$ & $1 \cdot 5 \quad(0 \cdot 9$ to $2 \cdot 2)$ \\
$\begin{array}{l}\text { High risk category (including erosions that bled on touch, } \\
\text { small growths, suspicious looking cervix) }\end{array}$ & $5135(11 \cdot 4)$ & $149(63)$ & $29 \quad(24 \cdot 4$ to 33.6) \\
\hline Total & 44970 & 238 & $5 \cdot 3(4 \cdot 6$ to $5 \cdot 9)$ \\
\hline
\end{tabular}

TABLE III - Prevalence of cervical cancer according to different sumptoms and signs. Figures are percentages (numbers of cancers/numbers of patients)

\begin{tabular}{|c|c|c|c|c|}
\hline \multirow[b]{2}{*}{ Symptoms } & \multicolumn{3}{|c|}{ Signs } & \multirow{2}{*}{$\begin{array}{c}\text { Rates of } \\
\text { malignancy } \\
\text { (per 1000) }\end{array}$} \\
\hline & $\begin{array}{l}\text { Normal looking } \\
\text { cervix }\end{array}$ & $\begin{array}{l}\text { Low risk } \\
\text { category }\end{array}$ & $\begin{array}{l}\text { High risk } \\
\text { category }\end{array}$ & \\
\hline No symptoms & $(0 / 163)$ & $(0 / 99)$ & $(0 / 10)$ & \\
\hline Symptoms other than bleeding & $\begin{array}{c}1 \cdot 7 \\
(19 / 11353)\end{array}$ & $\begin{array}{c}1 \cdot 9 \\
(43 / 21608)\end{array}$ & $\begin{array}{c}22 \cdot 4 \\
(82 / 3659)\end{array}$ & 3.9 \\
\hline Menstrual problems & $\begin{array}{c}0 \cdot 6 \\
(1 / 1612)\end{array}$ & $\begin{array}{c}1.6 \\
(53109)\end{array}$ & $\begin{array}{c}17 \cdot 9 \\
(13 / 727)\end{array}$ & $3 \cdot 5$ \\
\hline Bleeding & $\begin{array}{c}1.9 \\
(1 / 512)\end{array}$ & $\begin{array}{c}14 \cdot 5 \\
(20 / 1379)\end{array}$ & $\begin{array}{c}73 \cdot 1 \\
(54 / 739)\end{array}$ & $28 \cdot 5$ \\
\hline Rate of malignancy (per 1000) & $1 \cdot 5$ & $2 \cdot 6$ & $29 \cdot 0$ & $5 \cdot 3$ \\
\hline
\end{tabular}

5135 women in the high risk group) were confirmed by biopsy.

\section{Discussion}

Cervical cancer is preventable, and cytological screening is the means of its control, but in developing countries, where the load of disease is heavy, nationwide cytology screening programmes are not possible for many years to come because of the paucity of trained staff. Therefore an alternative strategy is needed. These findings confirm our previous results (that about half of cancers at an early stage can be detected by direct inspection of the cervix) and show that early cervical cancer can be staged in the maternal and child health setting, where the women will be screened.

Analysis of the symptoms showed that none of the asymptomatic women had cervical cancer. The prevalence of cancer was similar in women with symptoms other than bleeding and with menstrual problems $(3 \cdot 93 / 1000$ and $3 \cdot 48 / 1000$, respectively), but increased to $28 \cdot 5 / 1000$ among women with bleeding symptoms$7 \cdot 3$-fold to $8 \cdot 2$-fold higher than in women with other symptoms. As 75 of women with cancers $(32 \%)$ had bleeding symptoms, by clinically screening all women in the maternal and child health setting and further referring only those with bleeding for further evaluation through smear testing or biopsy, almost a third of the cancers $(32 \%)$ could be detected. This is not an ideal strategy as it missed two thirds of the cancers.

Analysis of the examination by speculum showed that the prevalence of cancer was $1 \cdot 53 / 1000$ among women with a normal looking cervix, $2 \cdot 6 / 1000$ in women in the low risk category $(1.7$ times higher than in the reference group), and $29 / 1000$ in women in the high risk category (18.9 times higher than in the reference group). Thus, women with signs in the high risk category (cervical erosions that bled on touch, small growth, or a suspicious looking cervix) are a relevant group for any screening programme. In our study $11 \cdot 4 \%$ of the women belonged to this category and had $63 \%$ of the cancers. Thus, by visually screening all the women attending maternal and child health services and referring only those with "high risk" signs for cytological or colposcopic evaluation, almost two thirds $(63 \%)$ of the cancers can be detected in an early stage (stage 0-IIA). Further analysis (table III) showed that when women seen to have high risk symptoms plus those reporting bleeding symptoms $(15.6 \%$ of the maternal and child health services population) were evaluated through cytology or colposcopy, $71 \%$ of cancers were detected at an early stage.

Thus visual screening of women in the maternal and child health services is suboptimal compared with cytological screening. However, where the prevalence of cervical cancer is high and cytological screening not yet feasible, visual screening is still relevant as it will detect over $70 \%$ of cervical cancers when all women attending maternal and child health services are visually screened and only a small fraction are referred for further evaluation.

We thank Mr N S Murthy, assistant director (statistics), for statistical help.

1 Stjernsward J, Eddy D, Luthra UK, Stanley K. Plotting a new course for cervical cancer screening in developing countries. World Health Forum $1987 ; 8: 42-52$

2 Sehgal A, Singh V, Bhambhani S, Luthra UK. Screening for cervical cancer by direct inspection. Lancet 1991;338:282.

3 Snedecor GW, Cochran WG. Sampling from binomial distribution. In Statistical methods. 6th ed. Des Moines, Iowa: Iowa State University Press, 1967:199-227.

(Accepted 27 November 1991$)$ 